Hospital 1B300/0036, 1500 E Medical Center Dr, Ann Arbor, MI 48109).

COMMENT. The EEG may identify patients with infantile spasms whose lesions are amenable to surgery, even when not detected by clinical findings and imaging studies. Most cases showing asymmetric hypsarrhythmia had developmental abnormalities of the brain, primarily large cystic lesions. Cerebral tumors have been reported, eg. Branch CE and Dyken PR. Choroid plexus papilloma and infantile spasms. Ann Neurol 1979;5:302. The spasms resolved after surgery for removal of the tumor. These cases favor a primary cortical rather than brainstem origin for infantile spasms.

A generalized electrodecremental EEG resulting from a focal cortical ictal discharge and associated with partial seizures is reported in 23 patients seen at the Johns Hopkins Epilepsy Center (Arroyo S et al. Epilepsia 1994;35:974).

The surgical treatment of an early epileptic encephalopathy with suppression-bursts (Ohtahara's syndrome) and focal cortical dysplasia is reported from Hopital Pellegrin, Bordeaux, France (Pedespan JM et al. Epilepsia Jan 1995;36:37-40). Infantile spasms and brief left-sided tonic unilateral seizures began at 5 days of age. The interictal EEG showed an asymmetrical suppression-burst pattern affecting the right hemisphere. MRI showed right frontotemporal cortical thickening. Seizures were resistant to AEDs and steroid therapy. The right precentral area resected showed cytoarchitectural dysplasia and ectopic neurons deep in subcortical white matter. At 1 year follow-up, the child had suffered only a "febrile seizure," and had minor developmental delay with slight left-sided weakness. Surgery may be effective in some cases of Ohtahara's syndrome.

Sarnat HB, University of Washington, Seattle, reviews "Ependymal reactions to injury" and focal dysplasias of the developing brain that may be secondary to damage to fetal ependyma. (I Neuropathol Exp Neurol January 1995;54:1-15).

\title{
EPISODIC HYPERSOMNOLENCE EPILEPSY
}

A 4 year old child who had complex partial seizures alternating with sleep that presented as episodic hypersomnolence is reported from the Mayo Clinic, Rochester, MN. The hypersomnolence lasting 24-72 hrs was preceded by irritability and hyperkinesia for 48-96 hrs. The intervals between episodes ranged from 10-60 days. The EEG showed left occipital spikes in sleep. Prolonged recording during hypersomnolence showed right temporal seizure discharges. Phenytoin controlled the episodic hypersomnolence, with no recurrence at $19 \mathrm{yr}$ follow-up. Complex partial seizures followed by postictal somnolence occurred occasionally between 5 and $11 \mathrm{yrs}$ of age. CT was normal. Behavioral problems required special education and methylphenidate. He graduated from high school and has a manual labor job. (Wszolek ZK, Groover RV, Klass DW. Seizures presenting as episodic hypersomnolence. Epilepsia Jan 1995;36:108-110). (Reprints: Dr DW Klass, Section of Electroencephalography, Mayo Clinic, 200 First St SW, Rochester, MN 55905).

COMMENT. The EEG recording showing right temporal seizure discharges during the period of hypersomnolence. and the excellent response to phenytoin suggest that the episodic sleep disorder may be regarded as a seizure phenomenon. Lennox WG refers to "sleeplike episodes" and 
somnambulism as forms of epilepsy, but does not describe a case similar to the above report. (Epilepsy and Related Disorders. Boston, Little, Brown, 1960).

A young man presented with episodes of unexplained hypersomnolence lasting 24-48 hrs in my own practice. An EEG between episodes showed occasional temporal sharp waves. CT and metabolic studies were normal. An EEG recording during an attack could not be obtained. A trial of phenytoin was successful in this case, and attacks recurred when treatment was discontinued. A seizure disorder was suspected but not proven.

Sleep disorders with central hypoventilation syndrome and seizures is reviewed in Progress in Pediatric Neurology II, Chicago, PNB Publ, 1994, pp 192-4.

\section{TOXIC DISORDERS}

\section{ALCOHOL-RELATED PERINATAL BRAIN INJURY IN PREM'S}

The relation between maternal alcohol use and intraventricular hemorrhage in 349 prematures weighing $2000 \mathrm{~g}$ or less was examined by the Neonatal Brain Hemorrhage Study Team at the Epidemiology Department, Michigan State University, East Lansing, MI; National Institute of Environmental Health Sciences, Research Triangle Park, N Carolina; and the Dept of Pediatrics and Clinical Epidemiology, University of Pennsylvania School of Medicine, Philadelphia, PA. Infants of women reporting "high" alcohol use ( 7 or more drinks per week and/or 3 or more per occasion) during preganancy were at increased risk of developing brain hemorrhage and white matter damage. (Holzman $\mathrm{C}$ et al. Perinatal brain injury in premature infants born to mothers using alcohol in pregnancy. Pediatrics January 1995;95:6673).

COMMENT. Premature infants of mothers who are high alcohol consumers during pregnancy have an increased risk of brain damage. Mothers' alcohol use before pregnancy had no observed adverse effect on the infant. However, alcohol taken during breast feeding may cause delay in motor development. (see Progress in Pediatric Neurology I, Chicago, PNB Publ, 1991, pp448-50).

The fetal alcohol syndrome (FAS) in adolescence was studied in 44 patients followed for 10-14 years at the Department of Pediatrics, Rittberg Hospital of the German Red Cross, Berlin, Germany, and the Department of Child and Adolescent Psychiatry, University of Zurich, Switzerland. (Spohr HL et al. Acta Paediatr Nov 1994;404:19-26).

Although the pronounced growth retardation and dysmorphism of the early childhood FAS diminishes in the older child, a characteristic syndrome remains. The "juvenile" pattern of FAS showed the following features: microcephaly, growth retardation, cognitive deficits, behavioral problems, and craniofacial dysmorphism consisting of short palpebral fissures, thin upper lip, prominent nasal bridge, maxillary hypoplasia, strabismus, and malaligned teeth.

In a study of 64 families with alcoholism at the Karolinska Institute, Stockholm, Sweden, children had retarded development and more behavioral problems than controls until 4 years of age. Boys were more vulnerable than girls. Behavioral disorders were more 